\title{
APICAL TRANSPORTATION AND CENTERING RATIO IN S-CURVED CANALS USING NITI FULL ROTATION VERSUS RECIPROCATION SHAPING TECHNIQUES
}

\author{
Mohammed Hamdi Atteia*
}

\begin{abstract}
Objectives: The aim of the present study is to compare apical transportation, centering ratio, changes in working length and canal axis ratio in the S-shaped canals using full rotation versus reciprocation shaping techniques.

Methodology: Twenty-five S-curved artificial canals were used. Five canals were used for the pre-instrumentation radiographs and records. The other 20 canals were divided into two groups (10 canals each); G1: One-Shape $(O S)$ and G2: Wave-One (WO) files. Canals were prepared, and obturated. Post-obturation radiographs were taken with the same parameters of the pre-instrumentation records. Pre- and post-instrumentation digital images were evaluated with AutoCAD program analysis.
\end{abstract}

Results: Full rotation using $O S$ files showed significantly far less apical transportation than $W O$ reciprocation $(\mathrm{P}<0.001)$. There was no statistically significant difference in centering ratio between full rotating and reciprocating files $(\mathrm{P}>0.05)$. WO produced higher percentage increase in working length than $O S$ files. Both techniques could not maintain the original canal axis ratio.

Conclusions: Within the parameters of this study, Single-file shaping technique with full rotation instruments produced significantly less transportation and less violation of the working length than did the reciprocating $W O$ instruments. Both techniques violated the original canal axis ratio and had nearly equal centering ratio, however, none of them was perfectly centered.

KEYWORD: NiTi files, One-Shape, Wave-One, Canal shaping techniques, Single-file instrumentation technique, Full rotation, Reciprocating, Apical transportation, Centering ratio, Canal axis ratio.

* Associate Professor of Endodontics, Department of Endodontics, Faculty of Oral and Dental Medicine, Cairo University 


\section{INTRODUCTION}

Cleaning and shaping of the root canal is an important phase in endodontic treatment ${ }^{(1)}$. Development and marketing of nickel-titanium (NiTi) instruments has been a major development in endodontics. NiTi instruments have reduced operator fatigue, procedural errors, and the duration of the canal preparation. The mechanical properties of NiTi have enabled endodontic files to be more flexible, conform better to canal curvature, resist fracture, and wear less than stainless steel files ${ }^{(2)}$.

Canal instrumentation aims to achieve complete removal of vital or necrotic tissue to create sufficient space for irrigation. Furthermore, it aims to preserve the integrity and location of the canal and apical anatomy in preparation for an adequate filling. However, these objectives are adversely influenced by the highly variable root canal anatomy ${ }^{(3)}$. Introduction of less invasive instrumentation approaches maintains the original canal shape and is usually associated with better endodontic outcomes ${ }^{(4)}$.

The highly flexible NiTi rotary files allow less lateral forces to be exerted against the canal walls, especially in severely curved canals, reducing the risk of canal aberrations and transportation. However, these instruments may be subjected to breakage, mainly because of flexural (fatigue fracture) and torsional (shear failure) stresses ${ }^{(3)}$.

Various factors might contribute to increase these stresses, such as excessive pressure on the hand-piece, a wide area of contact between the canal walls and the cutting edge of the instrument, or if the canal lumen is smaller than the dimension of the non-active or non-cutting tip of the instrument ${ }^{(5)}$.

Canal curvature is considered one of the major risk factors for instrument failure caused by bending stresses (cyclic fatigue). Stresses due to bending cannot be significantly influenced by the clinician. However, the reciprocating motion might decrease the impact of cyclic fatigue on NiTi rotary instrument, compared with rotational motion ${ }^{(6)}$.
Wave-One (Dentsply/Maillefer, Ballaigues, Switzerland) is a NiTi single-file system that has been recently introduced into the market. The system is designed to be used with a dedicated reciprocating motion motor. It consists of 3 singleuse files: small (ISO 21 tip and 6\% taper) for fine canals; primary (ISO 25 tip and $8 \%$ taper) for the majority of canals; and large (ISO 40 and $8 \%$ taper) for large canals. The files are manufactured with M-Wire NiTi alloy ${ }^{(6)}$.

One-shape file is a single-use NiTi file which has been recently introduced by Micro-Mega (Micro-Mega, Besancon Cedex - France). The file is designed for full rotation motion with an ISO tip size of \#25. Micro-Mega claimed that the innovative unique design of the file with variable cross sections that progressively changes from apical (S-shaped triple helix) to coronal (S-shaped double-helix) would assure flexibility in curvatures and imparts optimal cutting action. The variable pitch and the Anti-Breakage Control (unwinding) of One-Shape are added features that reduce the screwing effect and instrument separation, respectively ${ }^{(7)}$.

The aim of the present study is to compare apical transportation, centering ratio, working length and canal axis ratio changes in the S-shaped (doublecurved) canals with full rotation versus reciprocation using single-file techniques.

\section{MATERIALS AND METHODS}

A total of 25 transparent ready-made clear epoxy resin blocks (Endo-Training-Bloc-S Dentsply/ Maillefer, Ballaigues, Switzerland) - of the same lot number - having a standardized dimensions and narrow simulated canals with double S-shaped curvatures and 0.02 taper were used.

\section{Determination of the original canal length and axis ratio}

Five Endo training blocks of the same batch number were randomly selected. Canals were injected with a radiopaque sealer AH26 Plus 
(Dentsply Detrey GmbH, Germany). Blocks were digitally radiographed and evaluated for the original (pre-instrumentation) canal length and axis ratio, using a technique that will be described in the following sections. Canal axis ratio $\left(\mathrm{Ax}_{\mathrm{r}}\right)$ was determined for both curves by dividing the radius measurement $(\mathrm{r})$ by the angulation value $\left(\mathrm{A}^{\circ}\right)$ and multiplying the result by one-hundred $\left(\mathrm{Ax}_{\mathrm{r} 0}=\left[\mathrm{r} / \mathrm{A}^{\circ}\right] \cdot 100\right)$ as per Berutti et al ${ }^{(6)}$.

\section{Radiographing Technique}

Pre- and Post-operative digital radiographs were taken using Gendex sensor (Gendex Imaging, 20095 Cusano, Milanino - Italy) and HelioDent DS x-ray machine (Sirona Dental Systems, GmbH, Germany). Sensors were secured in a fixed position in relation to the resin blocks. A rectangular orthodontic wire segment (of a predetermined length $=20 \mathrm{~mm}$ ) was attached to the resin block surface to obtain an image scale to calibrate the measurements. The radiographic parameters were set at $60 \mathrm{kV}, \mathrm{DC}, 7 \mathrm{~mA}$ and $0.1 \mathrm{Sec}$, fixed target-object distance $(15 \mathrm{~cm})$, where the tube of the $\mathrm{x}$-ray machine was stabilized in a reproducible position using the sensor holder device, (Fig-1).

\section{Canal Preparation}

Twenty resin blocks were divided equally into two groups, ten blocks each. Group-I: OneShape (full rotation), and group-II: Wave-One (reciprocation).

\section{Coronal Third Preparation}

Preflaring the coronal third just before the $1^{\text {st }}$ curve for all specimens was done using ProTaper Universal Sx instrument (Dentsply/Maillefer, Ballaigues, Switzerland) rotated in a brushing motion with a motor settings of $250 \mathrm{rpm}$ and 3.5 Ncm using VDW endo-motor (VDW, Dentsply, Italy) and a 6:1 gear reduction hand-piece (Sirona/ Dentsply, Maillefer). The endo-motor has the ability to shift between different preset or customized programs for different up-to-date NiTi rotary systems. K-file size \#10 (Colorinox Dentsply/ Maillefer, Ballaigues, Switzerland) instrument was used as a patency file, recapitulating file, and in agitating the irrigating solution before flushing. Chelating gel (DiaPrep Plus, DiaDent - Korea) was used with all instruments. Irrigation was done using $2.6 \% \mathrm{NaOCl}$ solution between instruments.

\section{Group-I (One-Shape full rotation technique)}

A glide path to the full working length was created using G1 followed by G2 files (MicroMega, Besancon Cedex, France) adjusted to the full working length at $400 \mathrm{rpm}$ and $3 \mathrm{Ncm}$. OneShape file (Micro-Mega, Besancon Cedex, France) was adjusted to the full WL and started to prepare the canal in three phases or waves of motion; the coronal $2 / 3$, the WL-3mm, and the full WL at 400 rpm and $3 \mathrm{Ncm}$. Attempting to get the One-Shape file to the full WL in one single apical-ward motion, carries the risk of either; instrument separation, canal ledging, or screwing and sucking-in of the rotating instrument beyond the apex.

\section{Group-II (Wave-One reciprocation technique)}

A glide path to the full working length was done using the small Wave-One (yellow 21/0.06) file (Dentsply/Maillefer, Ballaigues, Switzerland) adjusted to the full working length, because size \#10 K-file was resistant to passively reach the full working length. The primary (red 25/0.06) WaveOne file was then used to prepare the canal to the full WL.

\section{Post-obturation Radiographs}

Canals of both groups were obturated using single-cone-matched gutta percha technique and AH26 plus sealer. Canals were radiographed using the same technique described earlier. Obturation of the canals provides the required canals' radio-opacity and enhances the accuracy of post-instrumentation measurements. The obtained radiographs were 
transferred for post-instrumentation evaluation using digital image processing and engineering programs.

\section{Digital Image-Processing and Engineering Softwares}

Adobe Photoshop CS5 software (Adobe Systems Inc, San Jose, CA) was used to enhance the edges of the initial uninstrumented and the finally instrumented and obturated digital radiographs. Images were then transferred to the AutoCAD geometrical processing and engineering software (AutoCAD 2010; Autodesk Inc, San Rafael, CA) to determine image scale, to measure canal length, angles and radii of curvature and to evaluate canal transportation and centering ratio at the apical third. The angle and radius of canal curvature were determined according to the methodology of Pruett et al ${ }^{(8)}$, (Fig. 2).

\section{Evaluation of Apical Transportation}

The amount of canal apical third transportation was determined by measuring the distance from the edge of uninstrumented canal to the periphery of the resin block (right and left) and then comparing this with the same measurements obtained from the postobturation images. Right and left measurements were taken at $3 \mathrm{~mm}$ from the apical end of the canal, (Fig. 3).

All values were measured by 2 evaluators, and a mean value was taken. The formula of Gergi et $a l^{(9)}$ was used for the calculation of transportation: I(a1 - a2) - (b1 - b2), where a1 is the distance from the left edge of the resin block to the left edge of the uninstrumented canal, b1 is the distance from the right edge of the resin block to the right edge of the uninstrumented canal, a2 is the distance from the left edge of the resin block to the left edge of the instrumented canal, and b2 is the distance from the right edge of the resin block to the right edge of the instrumented canal, (Fig. 3). According to this formula, a result other than " 0 " indicates that transportation has occurred in the canal.

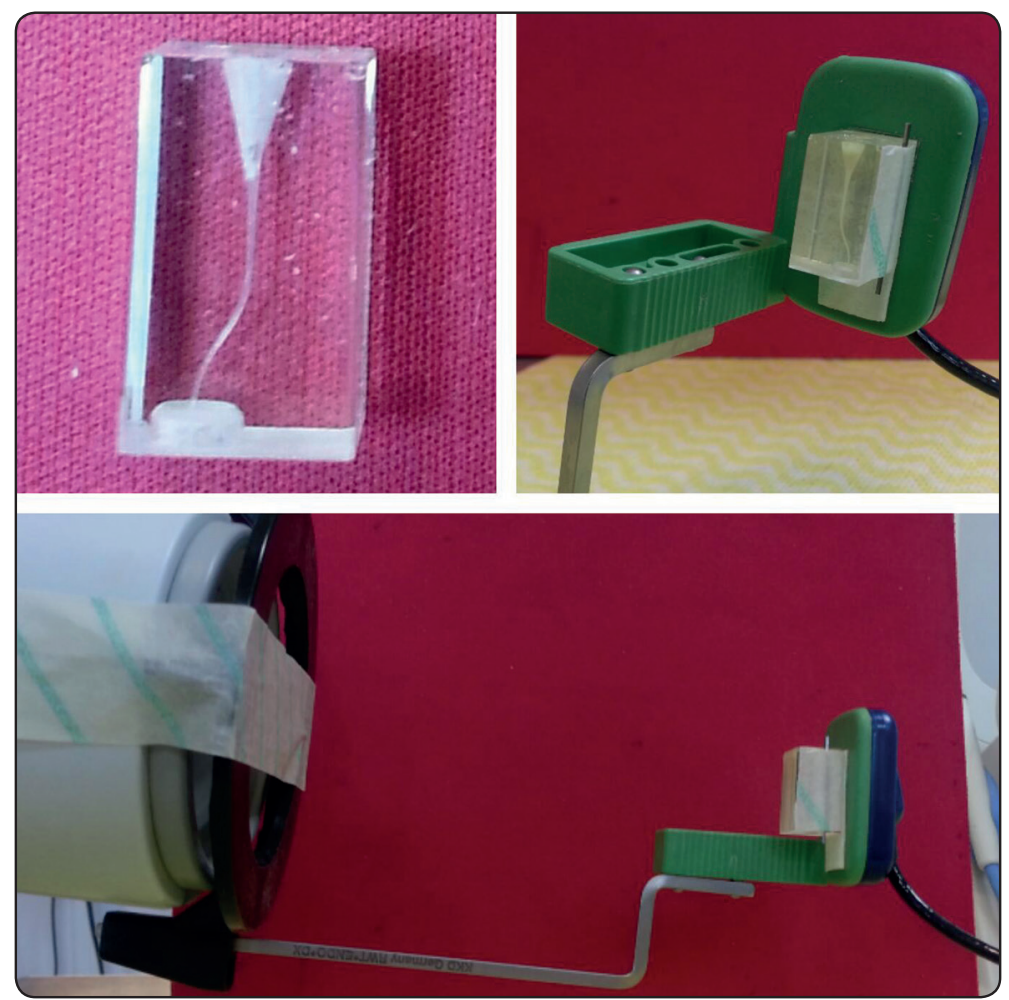

Fig. (1) Radiographic evaluation assembly. 


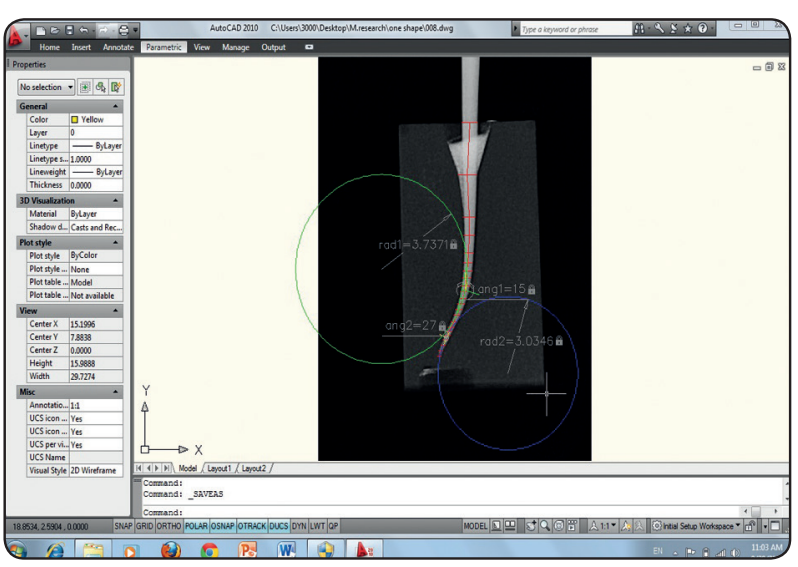

Fig. (2) AutoCAD analysis of length and curvatures.

\section{Evaluation of Apical Centering Ratio}

According to Gergi et al ${ }^{(9)}$, the mean centering ratio indicates the ability of the instrument to stay centered in the canal. It was calculated by using the following ratio: $(a 1-a 2) /(b 1-b 2)$ or $(b 1-b 2) /$ $(\mathrm{a} 1-\mathrm{a} 2)$. If these numbers are not equal, the lower figure is considered as the numerator of the ratio. According to this formula, a result of 1 indicates perfect centering.

Student t-test was used to statistically compare the mean values of canal transportation and centering ratio of the two shaping techniques.

\section{RESULTS}

The calculated digital image scale was found to be 2.057. All uninstrumented canals showed an average pre-operative length of $16.5 \mathrm{~mm}, 1^{\text {st }}$ angle of curvature of $18^{\circ}$ and a radius of $4.4 \mathrm{~mm}$, and $2^{\text {nd }}$ angle of curvature of $26^{\circ}$ and $3.8 \mathrm{~mm}$ radius. These curvatures are severe curvatures according to the classification of Torres et al ${ }^{(10)}$ (Fig. 2).

\section{Working Length Changes and canal Axis ratio}

The original (pre-instrumentation) canal axis ratio $\left(\mathrm{Ax}_{\mathrm{r} 0}\right)$ was calculated to be 0.2 for the coronal curve and 0.15 for the apical curve. Postinstrumentation $\mathrm{Ax}_{\mathrm{r} 1}$ was calculated for the $W O$ and $O S$ groups and the percentage change in canal axis

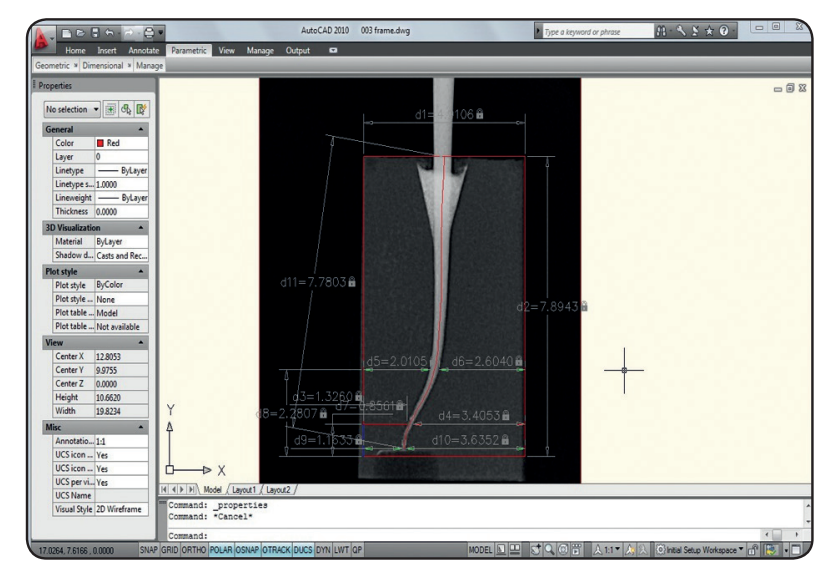

Fig. (3) AutoCAD measurements to determine apical transportation and centering ratio.

ratio (CAR) was calculated from the equation $\Delta \mathrm{Ax}_{\mathrm{r}}$ $=\left[\mathrm{Ax}_{\mathrm{r} 1} / \mathrm{Ax}_{\mathrm{r} 0}\right] * 100$ (tables; $\left.1 \& 2\right)$. In the coronal curve, One-Shape file had a lower percentage of CAR change than the Wave-One file. In the apical curve, One-Shape file had a greater change of the percentage of CAR (table 2).

TABLE (1) Pre-instrumentation angle $\left(\mathrm{A}^{\circ}\right)$ and radius (r) records

\begin{tabular}{|c|c|c|}
\hline Curve & $\mathbf{r}$ & $\mathbf{A}^{\mathbf{0}}$ \\
\hline Coronal & $\mathrm{r} 0=4.4$ & $\mathrm{Ao}=18$ \\
\hline Apical & $\mathrm{r} 0=3.8$ & $\mathrm{Ao}=26$ \\
\hline
\end{tabular}

\section{Apical Transportation}

Wave-One file showed more apical transportation $(5.1 \mathrm{~mm})$ than One-Shape $(0.4 \mathrm{~mm})$. Differences were statistically significant $\mathrm{P} \leq 0.001$ (Tables: 3,4 \& 5) (Fig. 4). The minus sign indicates the outward (shift to the right) direction of transportation and vice versa.

\section{Apical Centering Ratio}

Wave-One file showed more centering (0.5) than One-Shape $(0.4 \mathrm{~mm})$. Differences were statistically non-significant $\mathrm{P}>0.05$ (Table 4) (Fig. 5). The minus sign indicates shift to the right. 
TABLE (2) Post-instrumentation angle (Ao) and radius (r) records and canal axis ratio changes ( $\Delta \mathrm{AXr})$

\begin{tabular}{|l|c|c|c|c|c|c|}
\hline Group & Curve & $\mathbf{r}$ & $\mathbf{A}^{\mathbf{0}}$ & $\mathbf{A X r 1}$ & $\mathbf{A X r 0}$ & $\boldsymbol{\Delta} \mathbf{A X r}$ \\
\hline OS (I) & Coronal & 3.6 & 22 & 0.16 & 0.2 & 80 \\
\hline & Apical & 7.3 & 23 & 0.32 & 0.15 & 213 \\
\hline WO (II) & Coronal & 5.5 & 15 & 0.36 & 0.2 & 180 \\
\hline & Apical & 6.5 & 28 & 0.23 & 0.15 & 153 \\
\hline
\end{tabular}

TABLE (3) One-Shape (Full rotation technique) apical transportation records.

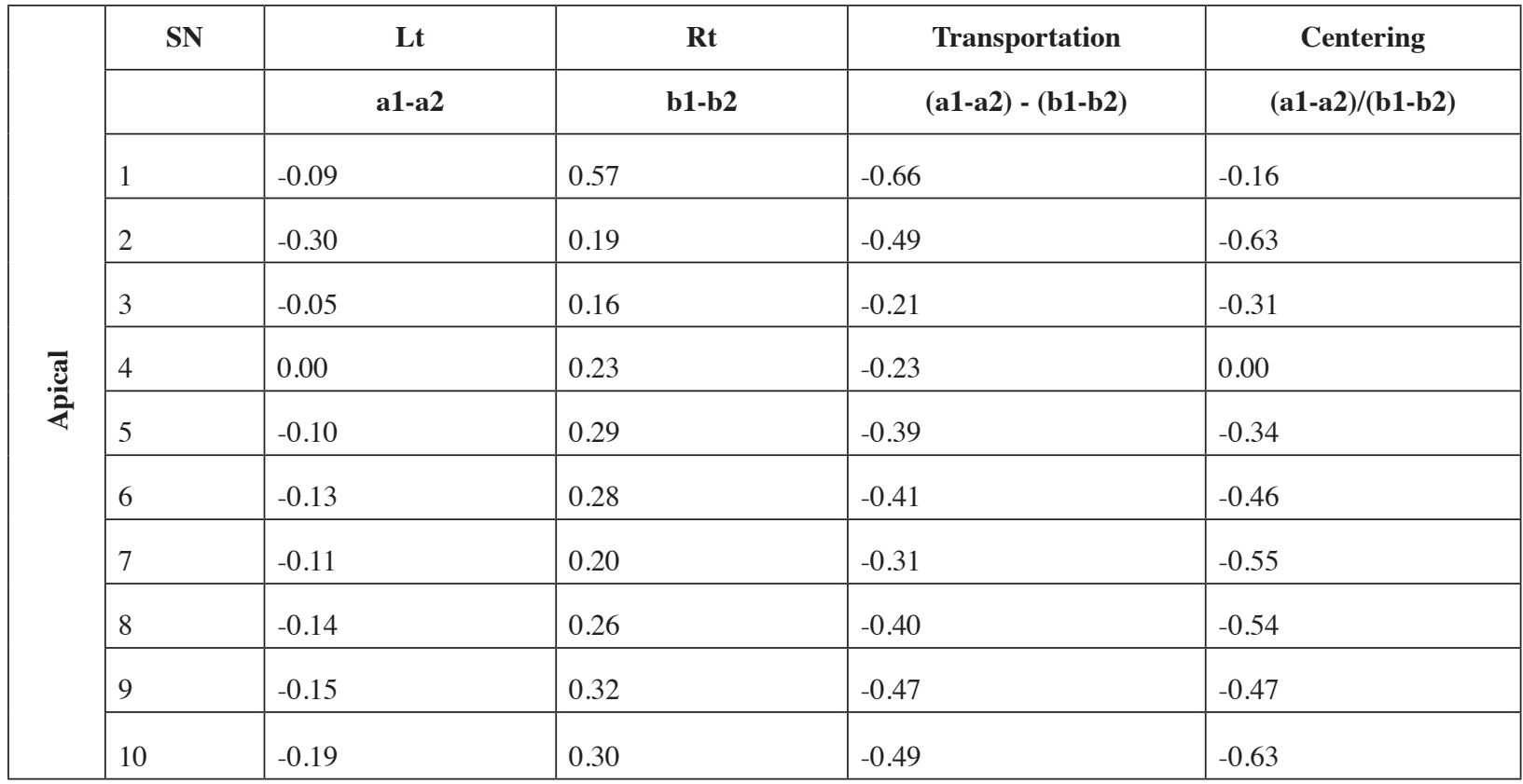

TABLE (4) Wave-One (Reciprocation technique) apical transportation records.

\begin{tabular}{|c|c|c|c|c|c|}
\hline \multirow{12}{*}{ 焉 } & \multirow{2}{*}{ SN } & $\mathbf{L t}$ & $\mathbf{R t}$ & Transportation & Centering \\
\hline & & a1-a2 & b1-b2 & $(\mathbf{a} 1-\mathbf{a} 2)-(\mathbf{b 1}-\mathrm{b} 2)$ & $(\mathbf{a} 1-\mathrm{a} 2) /(\mathrm{b} 1-\mathrm{b} 2)$ \\
\hline & 1 & -1.07 & 4.01 & -5.08 & -0.27 \\
\hline & 2 & -1.07 & 4.01 & -5.08 & -0.27 \\
\hline & 3 & -2.62 & 1.65 & -4.27 & -0.63 \\
\hline & 4 & -2.45 & 2.82 & -5.27 & -0.87 \\
\hline & 5 & -2.77 & 2.71 & -5.48 & -0.98 \\
\hline & 6 & -2.37 & 2.64 & -5.01 & -0.90 \\
\hline & 7 & -1.07 & 4.01 & -5.08 & -0.27 \\
\hline & 8 & -1.07 & 4.01 & -5.08 & -0.27 \\
\hline & 9 & -1.07 & 4.01 & -5.08 & -0.27 \\
\hline & 10 & -1.07 & 4.01 & -5.08 & -0.27 \\
\hline
\end{tabular}


TABLE (5) Student-t test applied to the apical transportation results of both techniques.

\begin{tabular}{|c|c|c|}
\hline \multirow{12}{*}{ Apical } & OSFR & WOR \\
\hline & $(\mathbf{a} 1-\mathrm{a} 2)-(\mathrm{b} 1-\mathrm{b} 2)$ & $(\mathbf{a} 1-\mathrm{a} 2)-(\mathrm{b} 1-\mathrm{b} 2)$ \\
\hline & 0.66 & 5.08 \\
\hline & 0.49 & 5.08 \\
\hline & 0.21 & 4.27 \\
\hline & 0.23 & 5.27 \\
\hline & 0.39 & 5.48 \\
\hline & 0.41 & 5.01 \\
\hline & 0.31 & 5.08 \\
\hline & 0.40 & 5.08 \\
\hline & 0.47 & 5.08 \\
\hline & 0.49 & 5.08 \\
\hline Mean & 0.41 & 5.05 \\
\hline S.D. & 0.13 & 0.31 \\
\hline $\mathbf{N}$ & 10 & 10 \\
\hline t(cal) & \multicolumn{2}{|c|}{43.8} \\
\hline \multicolumn{3}{|c|}{$* * *(\mathrm{P}<=0.001)$} \\
\hline
\end{tabular}

OSFR:One-Shape full-rotation.

WOR:Wave-One reciprocation. ***:Highly significant

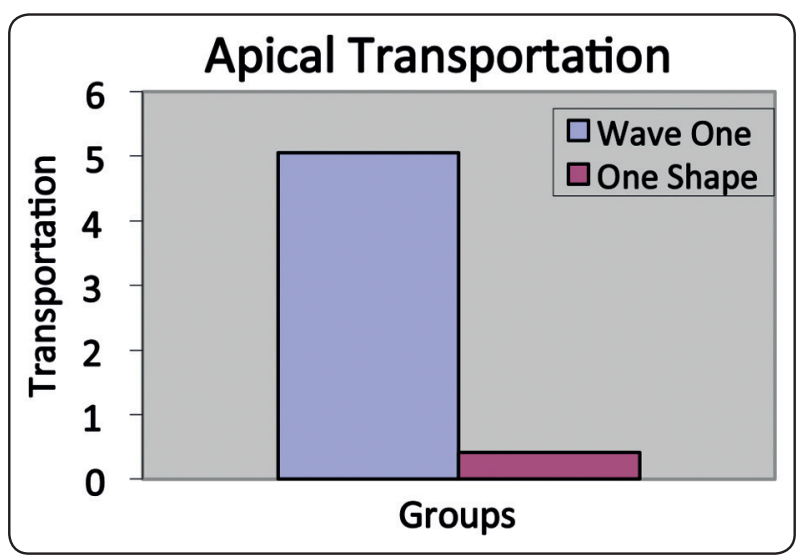

Fig. (4) Apical Transportation of full rotation (One-Shape) versus reciprocation (Wave-one) shaping techniques.
TABLE (6) Student-t test applied to the centering ratio results of both techniques.

\begin{tabular}{|c|c|c|}
\hline \multirow{4}{*}{} & OSFR & WOR \\
\cline { 2 - 3 } & (a1-a2)/(b1-b2) & (a1-a2)/(b1-b2) \\
\cline { 2 - 3 } & 0.16 & 0.27 \\
\cline { 2 - 3 } Apical & 0.63 & 0.27 \\
\cline { 2 - 3 } & 0.31 & 0.63 \\
\cline { 2 - 3 } & 0.00 & 0.87 \\
\cline { 2 - 3 } & 0.34 & 0.98 \\
\cline { 2 - 3 } & 0.46 & 0.90 \\
\cline { 2 - 3 } & 0.55 & 0.27 \\
\cline { 2 - 3 } & 0.54 & 0.27 \\
\hline \multirow{4}{*}{ t(cal) } & 0.47 & 0.27 \\
\hline \multirow{4}{*}{ Mean } & 0.63 & 0.27 \\
\hline S.D. & 0.41 & 0.50 \\
\hline \multirow{4}{*}{$\mathbf{N}$} & 0.21 & 0.31 \\
\hline
\end{tabular}

OSFR: One-Shape full-rotation.

WOR: Wave-One reciprocation

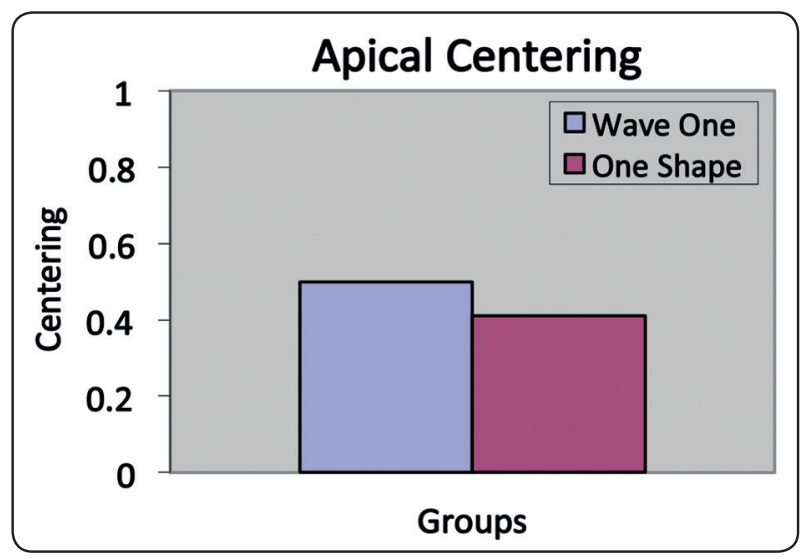

Fig. (5) Centering ratio of full rotation (One-Shape) versus reciprocation (Wave-one) shaping techniques. 


\section{DISCUSSION}

Maintaining the original canal anatomy is one of the main objectives in root canal cleaning and shaping (11). Shaping of curved canals can result in various procedural errors including canal transportation (12). Previous studies have shown that canal transportation leads to inappropriate dentin removal, with a high risk of straightening the original canal curvature and forming ledges in the dentin wall ${ }^{(13,14)}$.

The avoidance of both iatrogenic damage to the root canal structure and further irritation of the periradicular tissue is demanding for all the newest instrumentation techniques ${ }^{(15-16)}$. Maintaining the original canal shape using a less invasive approach is associated with better endodontic outcomes ${ }^{(4)}$.

Beside canal anatomy, other factors contribute to optimal mechanical instrumentation outcomes, such as instrument design, instrumentation sequence, rotational speed, operator's experience, and the use of irrigants ${ }^{(4,17)}$.

Recent studies showed that an alternating rotary movement is a valid option to optimize endodontic instrumentation by reducing the risk of instrument fracture and root canal deformity ${ }^{(18)}$.

In this study, the single-file technique was used with either the reciprocating or the continuous rotation motion in S-curved canals to compare their effect on the canal's length and the apical third regarding transportation and centering ability.

The single use of endodontic instruments was recently recommended to decrease instrument fatigue and possible cross-contamination (19), reducing the number of NiTi rotary instruments required for canal preparation. The single-file technique was also suggested as being costeffective ${ }^{(20)}$, and the learning curve is considerably reduced ${ }^{(21)}$. In their study, Berutti et al revealed that the use of single-file technique with the reciprocating motion enhanced the canal centering ability, leading to less invasive root canal preparation ${ }^{(3)}$.
Even though they do not represent the anatomic variability of a human root canal system, simulated resin canals have been widely used to point out differences in performance of instruments under standardized experimental conditions ${ }^{(22)}$.

Canal transportation and centering ability are reliable methods to evaluate the tendency of a shaping technique to maintain the original canal anatomy or to straighten the curves ${ }^{(23)}$

Several methods have been used to compare canal shape before and after preparation, including radiography ${ }^{(24)}$, serial sectioning technique (25) and CT imaging techniques ${ }^{(8,26-29)}$. It has recently been suggested that micro-computed tomographic 3-dimensional (3D) analysis is more discriminative of changes in the canal spaces associated with repeated instrument use than photographic measurements; however, volumetric changes only were assessed, and possible geometric changes were not analyzed ${ }^{(30)}$.

The present study used coronal preflaring and glide path creation prior to introducing the singlefile to the full working length. Many studies showed that coronal enlargement (31) and preliminary creation of a glide path are fundamental for safer use of NiTi rotary instrumentation. Preflaring tends to minimize procedural errors such as transportation and ledge formation. Indeed, preflaring permits to maintain a pathway to the full WL, avoiding excessive instrument binding in the canal ${ }^{(32,33)}$. Webber et al used reciprocating files after creation of a previous glide path, and found that it produced less modification in canal curvature than if used alone ${ }^{(34)}$.

However, excessive coronal flaring was found to increase the risk of strip perforation on the concave aspect of the curved roots ${ }^{(35)}$. Outer apical transportation and irregular foramen widening might lead to poor sealing efficiency with a high rate of extrusion of debris and postoperative discomfort ${ }^{(16,36,37)}$. 
Berutti et al concluded that the creation of a previous glide path before any NiTi rotary or reciprocating motion instrumentation appears to be appropriate for safely shaping the canal ${ }^{(6)}$.

S-curved canals were chosen to study their impact on the reciprocating or the rotating file while being subjected to a complex type of stresses in different directions. The rotating instrument inside the canal is subjected to two types of stresses, bending (cyclic fatigue) and torsional (shear) stresses. Canal curvature is considered one of the major risk factors for instrument failure caused by bending cyclic fatigue ${ }^{(4)}$; stresses due to bending cannot be significantly influenced by the clinician. The new M-Wire variant NiTi alloy instruments demonstrated better resistance on cyclic fatigue (flexural stresses) when compared with the same instrument design produced from stock 508 nitinol, preserving similar torsional properties ${ }^{(38)}$. Some studies also stated that the reciprocating motion might decrease the impact of cyclic fatigue on NiTi rotary instrument, compared with rotational motion $^{(18,39)}$.

Various aspects might contribute to increase the torsional shear stresses, such as excessive pressure on the handpiece ${ }^{(40)}$, wide area of contact between the canal walls and the cutting edge of the instrument ${ }^{(5,41)}$, or if the canal section is smaller than the dimension of the non-active or noncutting tip of the instrument (taper-lock).

The reciprocating movement minimizes torsional and flexural stresses, increases the canal centering ability, and reduces the taper lock within the number of instrument cycles within the root canal ${ }^{(42)(43)}$.

The results of the current study revealed superiority of One-Shape file, with full rotation, in maintaining canal anatomy with significantly less transportation and less violation of the working length than the Wave-one reciprocating file. This result is contradicting with a sum of studies that claimed that reciprocating motion increased canal centering ability and reduced the risk of root canal deformity (42-45). Berutti et al found the new Wave-One NiTi primary reciprocating single-file to be better in maintaining the original canal anatomy, with less modification of the canal curvature compared with the ProTaper system up to F2 ${ }^{(3)}$. Most of these studies used single curved experimental canals, while we used double-curved s-shape curved canals. Moreover, the geometrical design of One-shape file seems to play an important role which happens to be different from that of the full rotation files they used.

On the other hand, and in favor of our results, Schafer et al ${ }^{(46)}$ showed that One-Shape maintained canal curvatures in simulated S-shaped canals better than Wave-One files. They also found greater tendency to straighten the S-shaped canals. Diemer et $a l^{(47)}$, revealed that the behavior of instruments is linked to their geometry and their design. They claimed that the asymmetric triple helix crosssectional design (the same as in One-Shape) modifies the file behavior and increases safety.

None of the tested files maintained the original canal axis ratio. With the higher percentage of changes in coronal canal axis ratio produced by Wave-One, one should be careful to sweep away from the root furcation-side curvature to avoid accidental stripping. One-Shape file with higher percentage of canal axis ratio changes at the apical curve region, should be used cautiously in roots with thin and slim root apices.

The current study is in accordance with Schafer et $a l^{(48)}$, and Turker et $a l^{(49)}$, who found that OneShape produced much less debris extrusion. Apical extrusion of debris is more commonly related to inability to maintain the original working length.

Within the parameters of this study, the singlefile shaping technique with full rotation (OneShape) produced significantly less transportation and less violation of the working length than did the reciprocating Wave-One instruments. Both 
techniques had nearly equal centering ratio, however, neither of them was perfectly centered.

The author would like to express his gratitude and appreciation to Eng. Amal Swidan, (B.S.E.Eng, Cairo University, Ministry of Electricity - EET Co.), for the tremendous help and cooperation in performance and interpretation of mathematical data, Photoshop work and AutoCAD data analysis.

\section{REFERENCES}

1. Peters $\mathrm{O}$, Peters $\mathrm{C}$ : Cleaning and shaping of root canal system. In: Cohen S, Hargreaves K, Keiser K. Pathways of the pulp, 9th ed. St Louis, MO Elsevier, 2006.

2. Inan U, Gonulol N: Deformation and Fracture of Mtwo Rotary Nickel-Titanium Instruments After Clinical Use. J Endod 2009;35:1396-99.

3. Berutti E. Chiandussi G. Paolino DS. Scotti N. Cantatore G. Castellucci A. Canal Shaping with WaveOne Primary Reciprocating Files and ProTaper System: A Comparative Study. J Endod 2012;38:505-509

4. Peters OA. Current Challenges and concepts in the preparation of root canal systems: a review. J Endod 2004; 30:559-67.

5. Peters OA, Peters CI, Schonenberger K, Barbakow F. ProTaper rotary root canal preparation: assessment of torque and force in relation to canal anatomy. Int Endod J 2003;36:93-9

6. Berutti E. Paolino DS. Chiandussi G. et al. Root Canal Anatomy Preservation of WaveOne Reciprocating Files with or without Glide Path. J Endod 2012;38:101-104

7. www.oneshape-mm.com

8. Pruett JP, Clement DJ, Carnes DL Jr. Cyclic fatigue testing of nickel-titanium endodontic instruments. J Endod 1997;23:77-85.

9. Gergi R, Abou Rjeily J, Sader J, Naaman A: Comparison of Canal Transportation and Centering Ability of Twisted Files, Pathfile-ProTaper System, and Stainless Steel Hand K-Files by Using Computed Tomography J Endod 2010;36:904-7.

10. Torres DU, Gonza'lez-Rodrı'guez MP, Ferrer Luque CM: Effectiveness of a Manual Glide Path on the Preparation of Curved Root Canals by Using Mtwo Rotary Instruments. J Endod 2009;35:699-702.
11. Thomson SA, Dummer PMH: Shaping ability of Hero 642 rotary nickel-titanium instruments in simulated root canals: part 2. Int Endod J 2000;33:255-61.

12. Hulsmann M, Stryga F: Comparison of root canal preparation using different automated devices and hand instrumentation. J Endod 1993;19:141-5.

13. Jafarzadeh H, Abbott PV. Ledge formation: review of a great challenge in endodontics. J Endod 2007;33:1155-62.

14. Loizides AL, Kakavetsos VD, Tzanetakis GN, Kontakiotis EG, Eliades G. A comparative study of the effects of two nickel-titanium preparation techniques on root canal geometry assessed by microcomputed tomography. J Endod 2007;33:1455-9.

15. Hulsmann M, Peters OA, Dummer PMH. Mechanical preparation of root canals: shaping goals, techniques and means. Endod Top 2005;10:30-76.

16. Pak JG, White SN. Pain prevalence and severity before, during, and after root canal treatment: a systematic review. J Endod 2011;37:429-38.

17. Karabucak B, Gatan AJ, Hsiao C, Iqbal MK. A comparison of apical transportation and length control between EndoSequence and Guidance rotary instruments. J Endod 2010;36:123-5.

18. Varela-Patino P, Ibanez-Parraga A, Rivas-Mundina B, Cantatore G, Otero XL, Martin- Biedma B. Alternating versus continuous rotation: a comparative study of the effect on instrument life. J Endod 2010;36:157-9.

19. Azarpazhooh A, Fillery ED. Prion disease: the implications for dentistry. J Endod 2008;34:1158-66.

20. Yared G. Canal preparation using only one NiTi rotary instrument: preliminary observations. Int Endod J 2008;41:339-44.

21. De-Deus G, Moreira EJ, Lopes HP, Elias CN. Extended cyclic fatigue life of F2 Pro-Taper instruments used in reciprocating movement. Int Endod J 2010;43:1063-8.

22. Lim KC, Webber J. The validity of simulated root canals for the investigation of the prepared root canal shape. Int Endod J 1985;18:240-6.

23. Merrett SJ, Bryant ST, Dummer PM. Comparison of the shaping ability of RaCe and FlexMaster rotary nickel-titanium systems in simulated canals. J Endod 2006;32:960-2.

24. Iqbal MK, Maggiore F, Suh B, Edwards KR, Kang J, Kim $\mathrm{S}$. Comparison of apical transportation in four Ni-Ti rotary instrumentation techniques. J Endod 2003;29:587-91. 
25. Bramante CM, Berbert A, Borges RP. A methodology for evaluation of root canal instrumentation. J Endod 1987;13:243-5.

26. Rhodes JS, Pitt Ford TR, Lynch JA, Liepins PJ, Curtis RV. Microcomputed tomography: a new tool for experimental endodontology. Int Endod J 1999;32:165-70.

27. Bergmans L, Van Cleynenbreugel J, Wevers M, Lambrechts P. A methodology for quantitative evaluation of root canal instrumentation using micro-computed tomography. Int Endod J 2001;34:390-8.

28. Garip Y, Gu“ nday M. The use of computed tomography when comparing nickel titanium and stainless steel files during preparation of simulated curved canals. Int Endod J 2001;34:452-7.

29. Peters OA, Laib A, Gohring TN, Barbakow F. Changes in root canal geometry after preparation assessed by high resolution computed tomography. J Endod 2001;27:1-6.

30. Ounsi HF, Franciosi G, Paragliola R, et al. Comparison of two techniques for assessing the shaping efficacy of repeatedly used nickel-titanium rotary instruments. J Endod 2011;37:847-50.

31. Roland DD, Andelin WE, Browning DF, Hsu GH, Torabinejad M. The effect of preflaring on the rates of separation for 0.04 taper nickel titanium rotary instruments. J Endod 2002;28:543-5.

32. Berutti E, Negro AR, Lendini M, Pasqualini D. Influence of manual preflaring and torque on the failure rate of ProTaper rotary instruments. J Endod 2004;30:228-30.

33. Patino PV, Biedma BM,Li_ebana CR, Cantatore G, Bahillo JG. The influence of a manual glide path on the separation rate of NiTi rotary instruments. J Endod 2005;31:114-6.

34. Webber J, Machtou P, Pertot W, Kuttler S, Ruddle C, West J. The WaveOne single-file reciprocatingsystem. Roots 2011;1:28-33.

35. Plotino G, Grande NM, Falanga A, Di Giuseppe IL, Lamorgese V, Somma F. Dentine removal in the coronal portion of root canals following two preparation techniques. Int Endod J 2007;40:852-8.

36. Wu MK, Fan B, Wesselink PR. Leakage along apical root fillings in curved root canals: part I-effects of apical transportation on seal of root fillings. J Endod 2000;26:210-6.

37. Siqueira JF Jr, Rocas IN, Favieri A, et al. Incidence of postoperative pain after intracanal procedures based on an antimicrobial strategy. J Endod 2002;28:457-60.

38. Johnson E, Lloyd A, Kuttler S, Namerow K. Comparison between a novel nickeltitanium alloy and 508 nitinol on the cyclic fatigue life of ProFile 25/.04 rotary instruments. J Endod 2008;34:1406-9.

39. You SY, Bae KS, Baek SH, Kum KY, Shon WJ, Lee W. Lifespan of one nickel-titanium rotary file with reciprocating motion in curved root canals. J Endod 2010;36: 1991-4.

40. Kobayashi C, Yoshioka T, Suda H. A new engine-driven canal preparation system with electronic canal measuring capability. J Endod 1997;23:751-4.

41. Blum JY, Cohen P, Machtou P, Micallet JP. Analysis of forces developed during mechanical preparation of extracted teeth using ProFile NiTi rotary instruments. Int Endod J 1999;32:24-31.

42. Southard DW, Oswald RJ, Natkin E. Instrumentation of curved molar root canals with the Roane technique. J En$\operatorname{dod} 1987 ; 13: 479-89$.

43. Roane JB, Sabala C. Clockwise or counterclockwise. J Endod 1984;10:349-53.

44. Roane JB, Sabala CL, Duncanson MG Jr. The "balanced force" concept for instrumentation of curved canals. J Endod 1985;11:203-11.

45. Franco V, Fabiani C, Taschieri S, Malentacca A, Bortolin M, Del Fabbro M. Investigation on the shaping ability of nickel-titanium files when used with a reciprocating motion. J Endod 2011;37:1398-401.

46. Saleh AM, Vakili Gilani P, Schafer E. Shaping ability of 4 different single-file systems in simulated S-shaped canals. J Endod. 2015;41:548-52.

47. Diemer F, Michetti J, Mallet JP, Piquet R. Effect of asymmetry on the behavior of prototype rotary triple helix root canal instruments. J Endod. 2013;39:829-32.

48. Burklein S, Benten S, Schafer E. Quantitative evaluation of apically extruded debris with different single-file systems: Reciproc, F360 and OneShape versus Mtwo. Int Endod J. 2014;47:405-9.

49. Türker SA, Uzunoğlu E, Aslan MH. Evaluation of apically extruded bacteria associated with different NickleTitanium systems. J Endod 2015; 41:953-5. 